\title{
NanoSIMS imaging of D/H ratios on FIB sections
}

Dan Lévy, Jérôme Aléon, Alice Aléon-Toppani, David Troadec, Rémi Duhamel, Adriana Gonzalez-Cano, Hélène Bureau, Hicham Khodja

\section{SUPPORTING INFORMATION}

Supporting information contains 1 table and 11 figures to supplement the manuscript describing NanoSIMS analytical conditions, data processing, erosion effects and detector effects on $\mathrm{H}$ isotopes measurements. 
Table S-1: $\mathrm{H}_{2} \mathrm{O}$ content and $\mathrm{D} / \mathrm{H}$ ratio of standards used in the study

\begin{tabular}{|c|c|c|}
\hline Sample & $\mathrm{H}_{2} \mathrm{O}$ & $D / H\left(\times 10^{-4}\right)$ \\
\hline San Carlos olivine ${ }^{1}$ & $<30 \mathrm{ppm}$ & - \\
\hline Pyroxene 71-98* & $182+/-21 \mathrm{ppm}$ & - \\
\hline Bancroft Sodalite* & $482+/-57 \mathrm{ppm}$ & - \\
\hline Bancroft Nepheline* & $505+/-51 \mathrm{ppm}$ & - \\
\hline Basaltic glass DR32² & 3099 ppm & 1.42 \\
\hline Illimaussaq amphibole 3 & $1.6 \mathrm{wt} \%$ & 1.33 \\
\hline Bamble amphibole ${ }^{3}$ & $2.0 w t \%$ & 1.46 \\
\hline CRPG Phlogopite ${ }^{4}$ & $2.4 \mathrm{wt} \%$ & 1.46 \\
\hline
\end{tabular}

* Measured by ERDA in this work

1. Chen, J.; Liu, H.; Girard, J. Comparative in Situ X-Ray Diffraction Study of San Carlos Olivine: Influence of Water on the $410 \mathrm{Km}$ Seismic Velocity Jump in Earth's Mantle. American Mineralogist 2011, 96 (5-6), 697-702. https://doi.org/10.2138/am.2011.3602.

2. Clog, M. Concentration et Composition Isotopique En Hydrogène Du Manteau Terrestre. thesis, Paris 7, 2010.

3. Engrand, C.; DeLoule, E.; Robert, F.; Maurette, M.; Kurat, G. Extraterrestrial Water in Micrometeorites and Cosmic Spherules from Antarctica: An Ion Microprobe Study. Meteoritics \& Planetary Science 1999, 34 (5), 773-786. https://doi.org/10.1111/j.19455100.1999.tb01390.x.

4. Govindaraju, K. Report (1968-1978) on Two Mica Reference Samples: Biotite Mica-Fe and Phlogopite Mica-Mg. Geostandards Newsletter 1979, 3 (1), 3-24. https://doi.org/10.1111/j.1751-908X.1979.tb00235.x. 


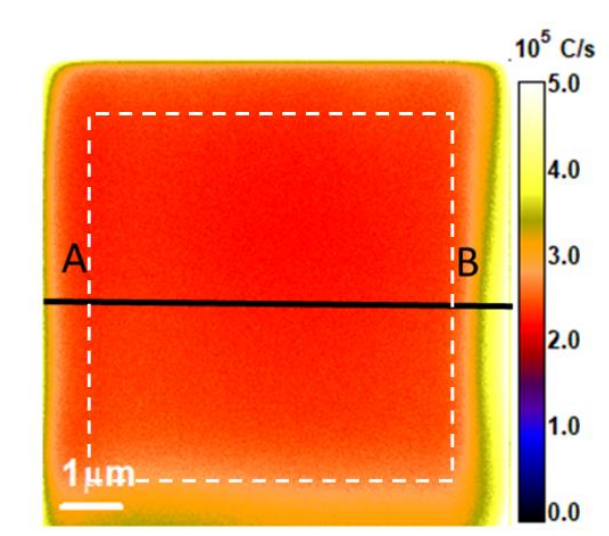

a)

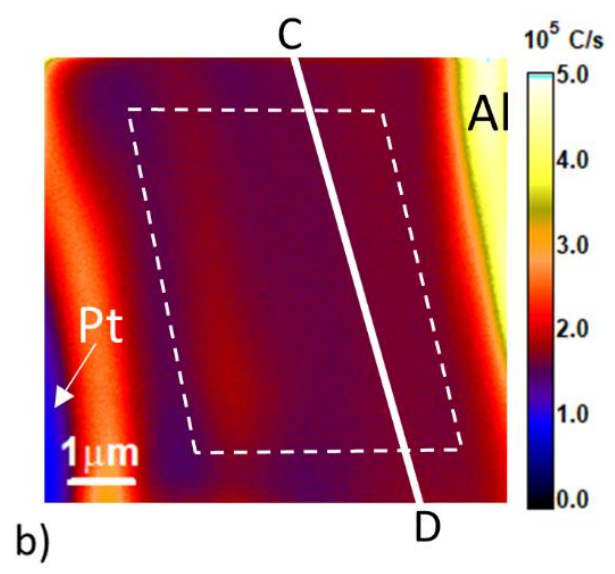

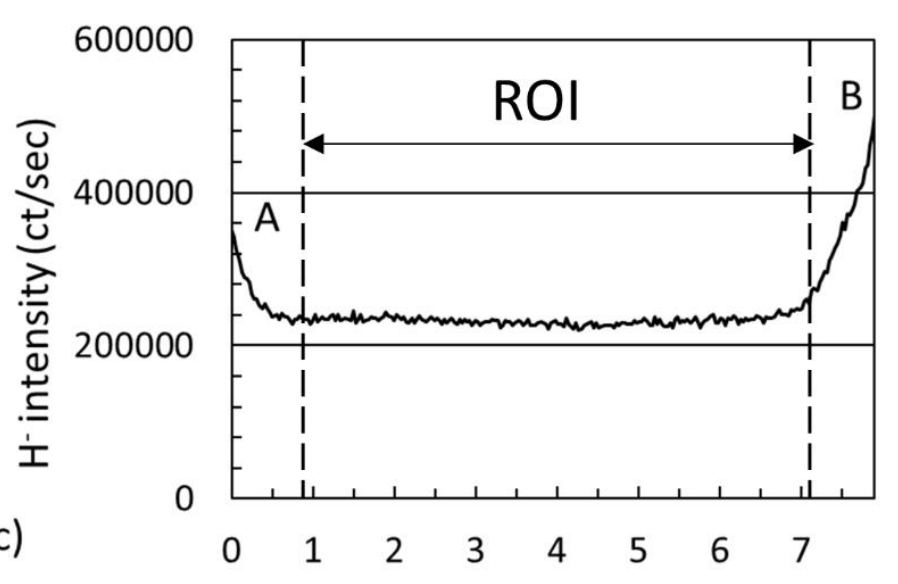

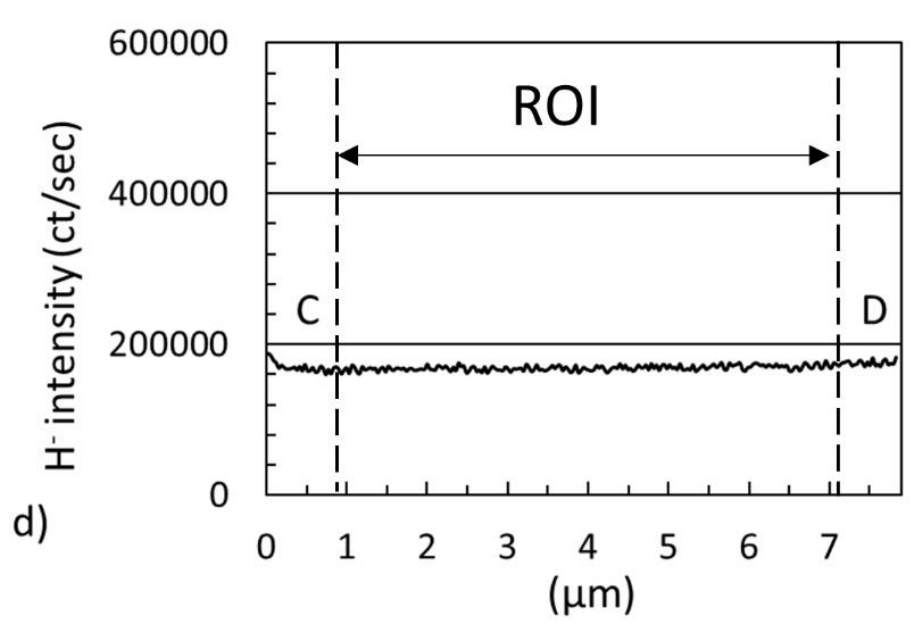

Figure S-1: a) Map of $\mathrm{H}$ intensity of Illimaussaq prepared on a polished section in epoxy and associated profile along line A-B; b) Map of $\mathrm{H}$ intensity of a FIB section of Illimaussaq deposited on an aluminium substrate and associated profiles along line C-D. Three types of edge effects possible (1) diffusion of surface atoms/molecules from neighbouring areas into the crater; (2) sampling of the immediate surroundings when the beam size is significantly larger than a few pixels; (3) topography effects due to crater depth. These images show that effects (1) and (2) associated with surface contamination are strongly reduced on FIB sections. To avoid effects associated with (2) and (3), intensities were extracted from a central $200 \times 200$ pixel area (shown here as white squares with dashed lines on images and lines in profiles). 

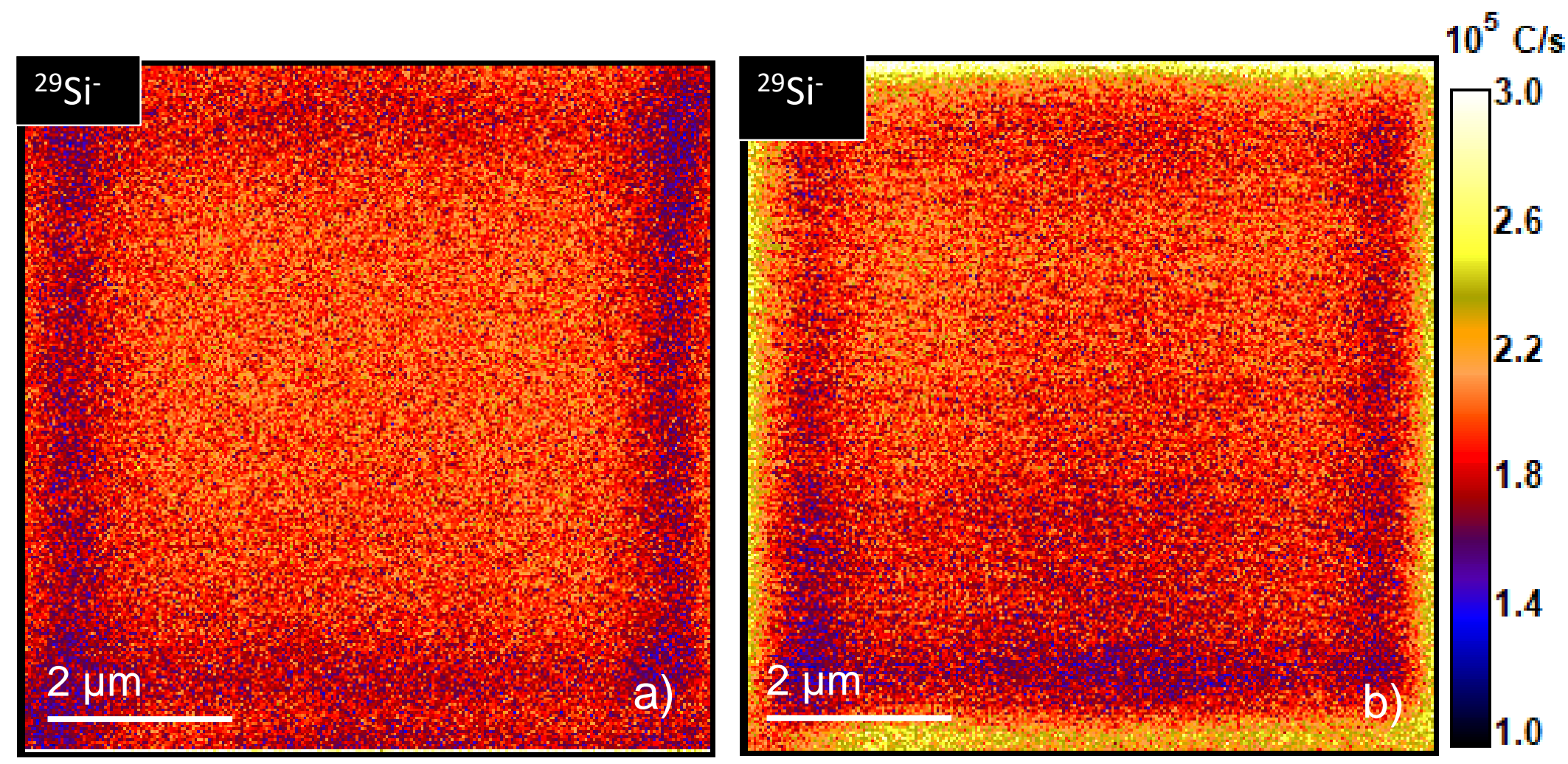

Figure S-2: ${ }^{29} \mathrm{Si}^{-}$intensity image of Illimaussaq amphibole polished section for a primary beam intensity of $200 \mathrm{pA}$. a) image without charging effects. b) image with charging visible as horizontal lines the image. 

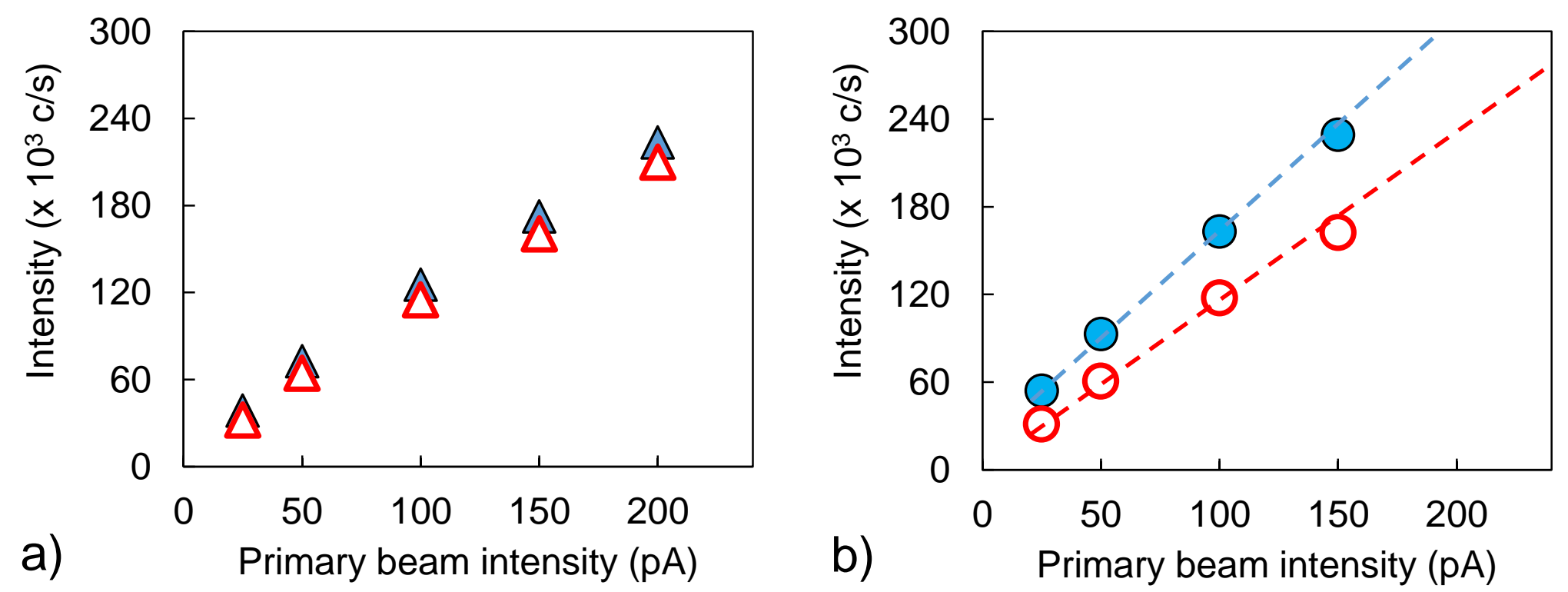

a) Primary beam intensity (pA)

O illim $\triangle$ bam $\square \mathrm{H}^{-} \quad \square{ }^{29} \mathrm{Si}^{-}$

Figure S-3: $\mathrm{H}^{-}$and ${ }^{29} \mathrm{Si}^{-}$intensity evolution with primary beam intensity of a) Bamble and b) Illimaussaq amphiboles 

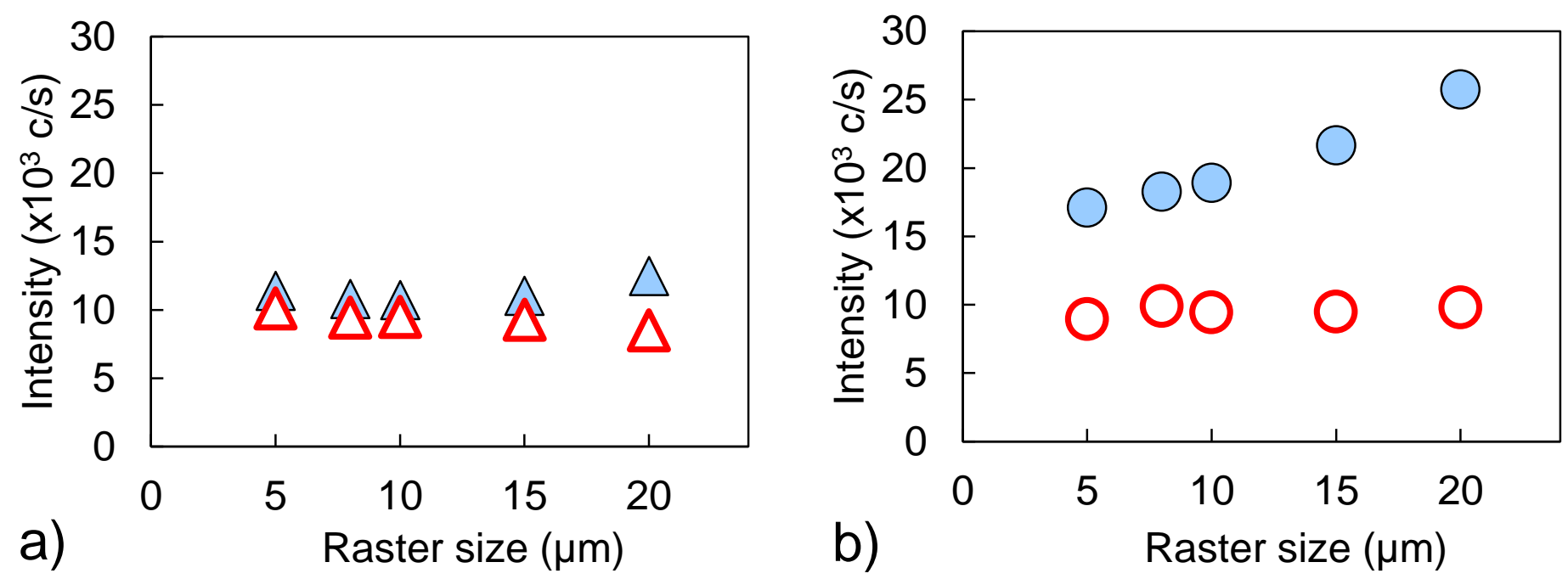

b)
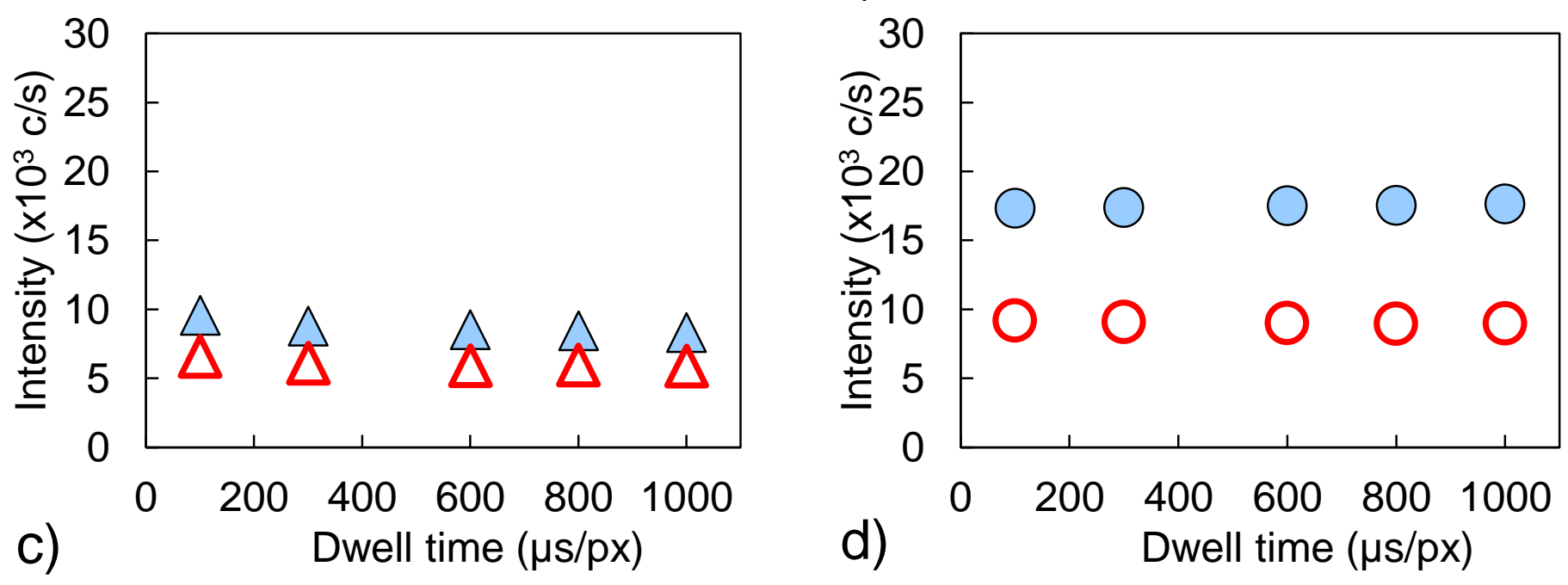

\begin{tabular}{|lll}
\hline O illim $\triangle$ bam $\square \mathrm{H}^{-} \square{ }^{29} \mathrm{Si}^{-}$ \\
\hline
\end{tabular}

Figure S-4: $\mathrm{H}^{-}$and ${ }^{29} \mathrm{Si}^{-}$intensity evolution with raster size (a) in Bamble and (b) in Illimaussaq and with dwell time (c) in Bamble and (d) in Illimaussaq for a primary beam intensity of $10 \mathrm{pA}$. 

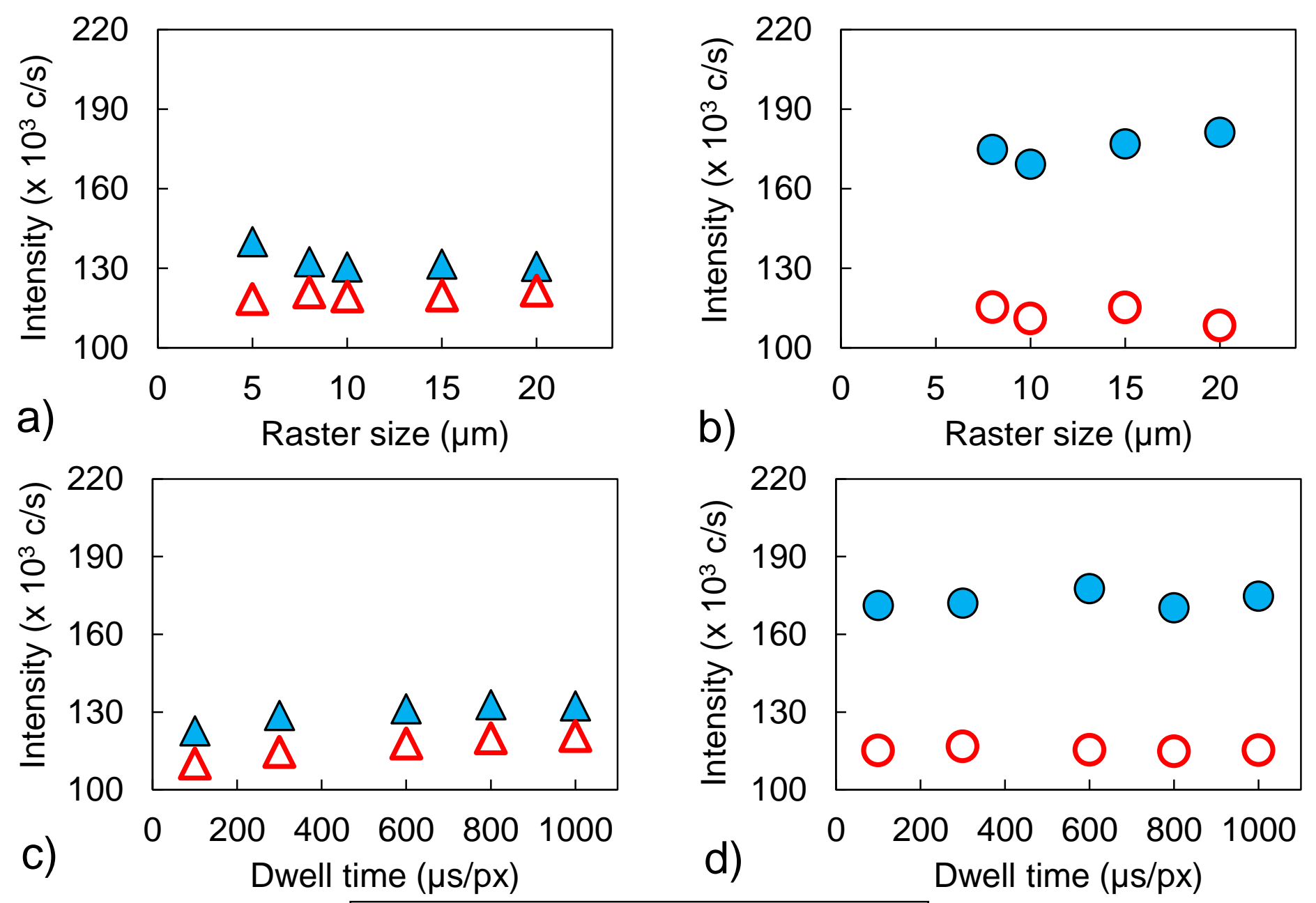

Figure S-5: $\mathrm{H}^{-}$and ${ }^{29} \mathrm{Si}^{-}$intensity evolution with raster size (a) in Bamble and (b) in Illimaussaq and with dwell time (c) in Bamble and (d) in Illimaussaq for a primary beam intensity of $100 \mathrm{pA}$. 


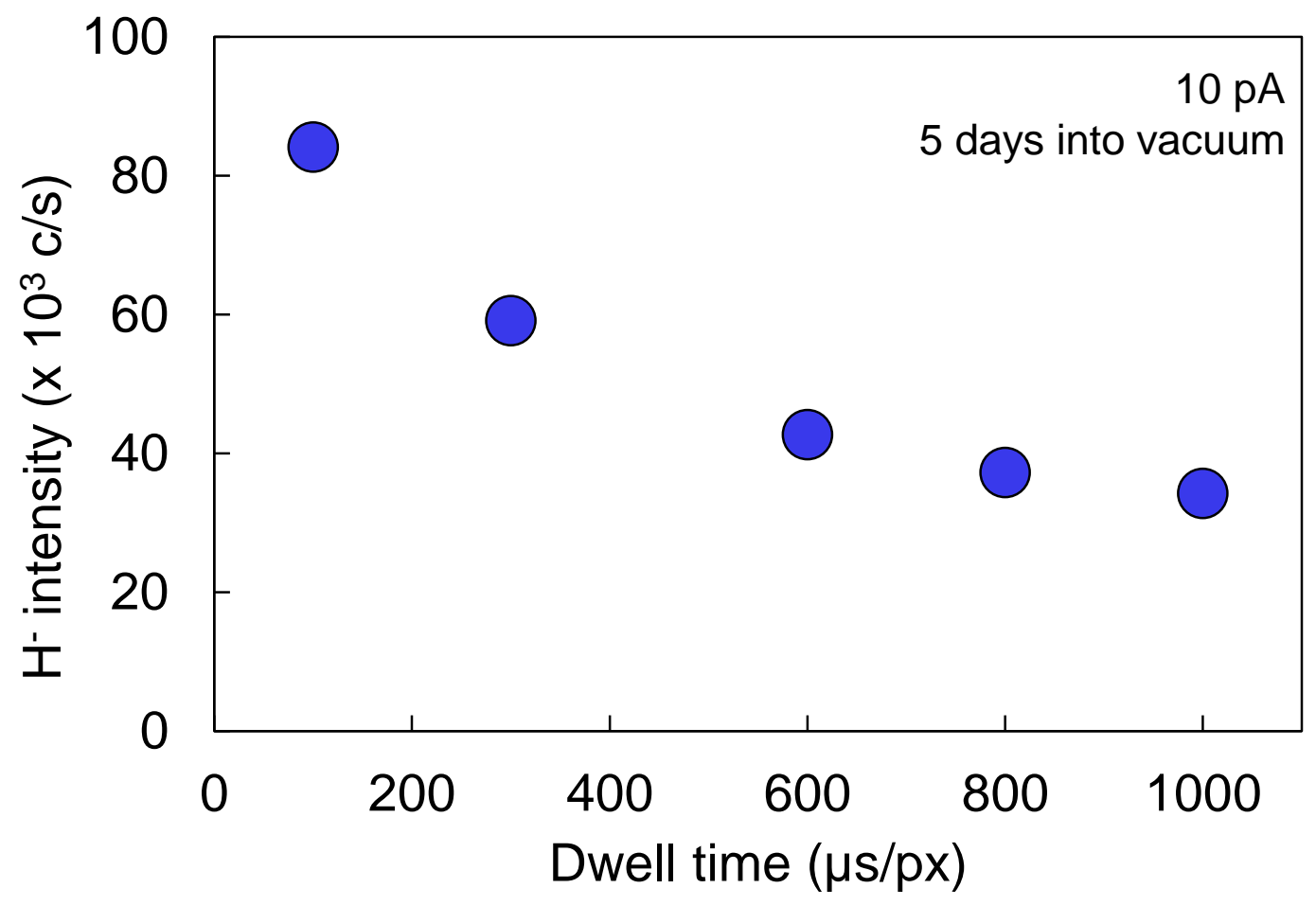

Figure S-6: $\mathrm{H}^{-}$intensity evolution with dwell time of Illimaussaq amphibole polished section for a primary beam intensity of 10 pA. Measurements were done in tuning mode, after 5 days into vacuum. 


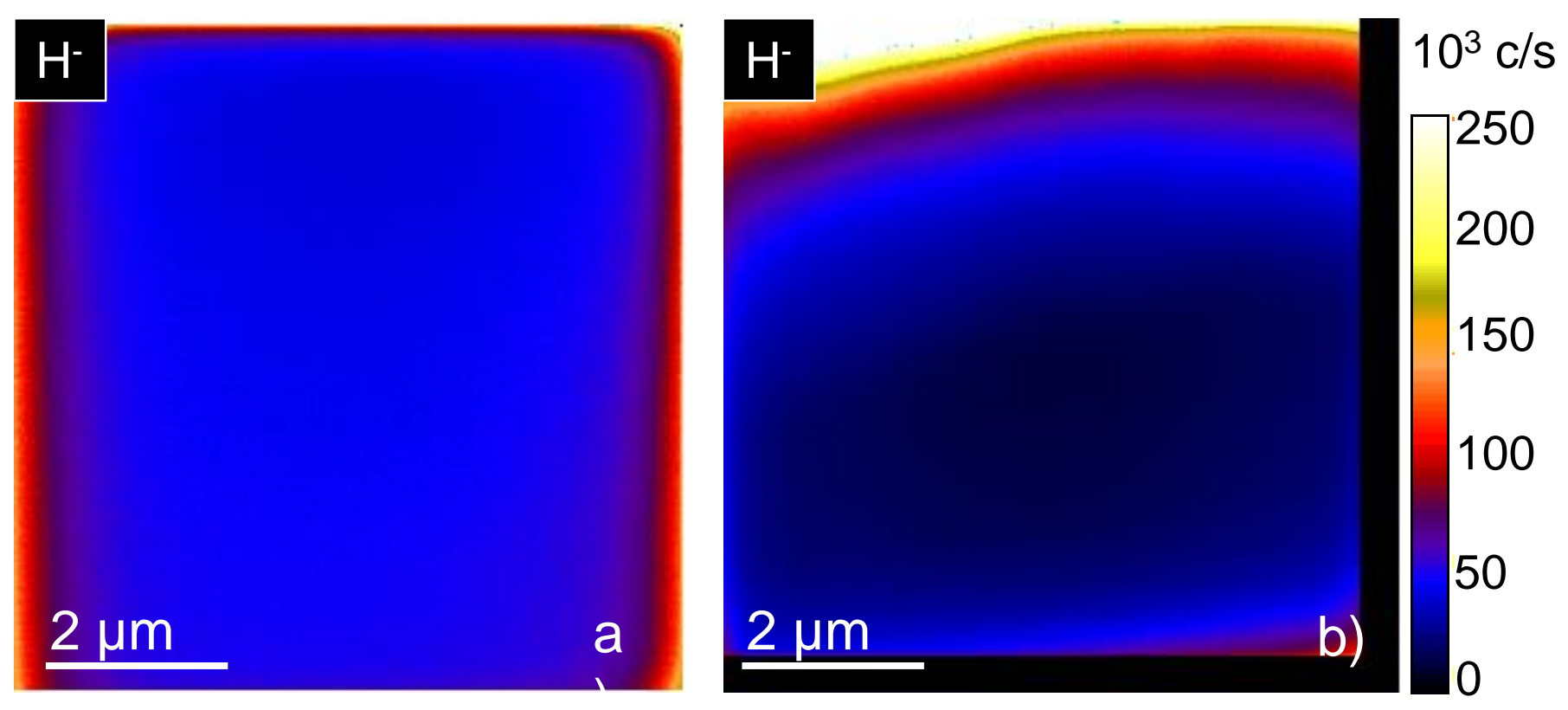

Figure S-7: Hydrogen intensity images of a) a polished section of 7198 pyroxene and $b$ ) a FIB section of 71-98 pyroxene. The difference in intensity is due to a larger amount of surface contamination on the polished section. 


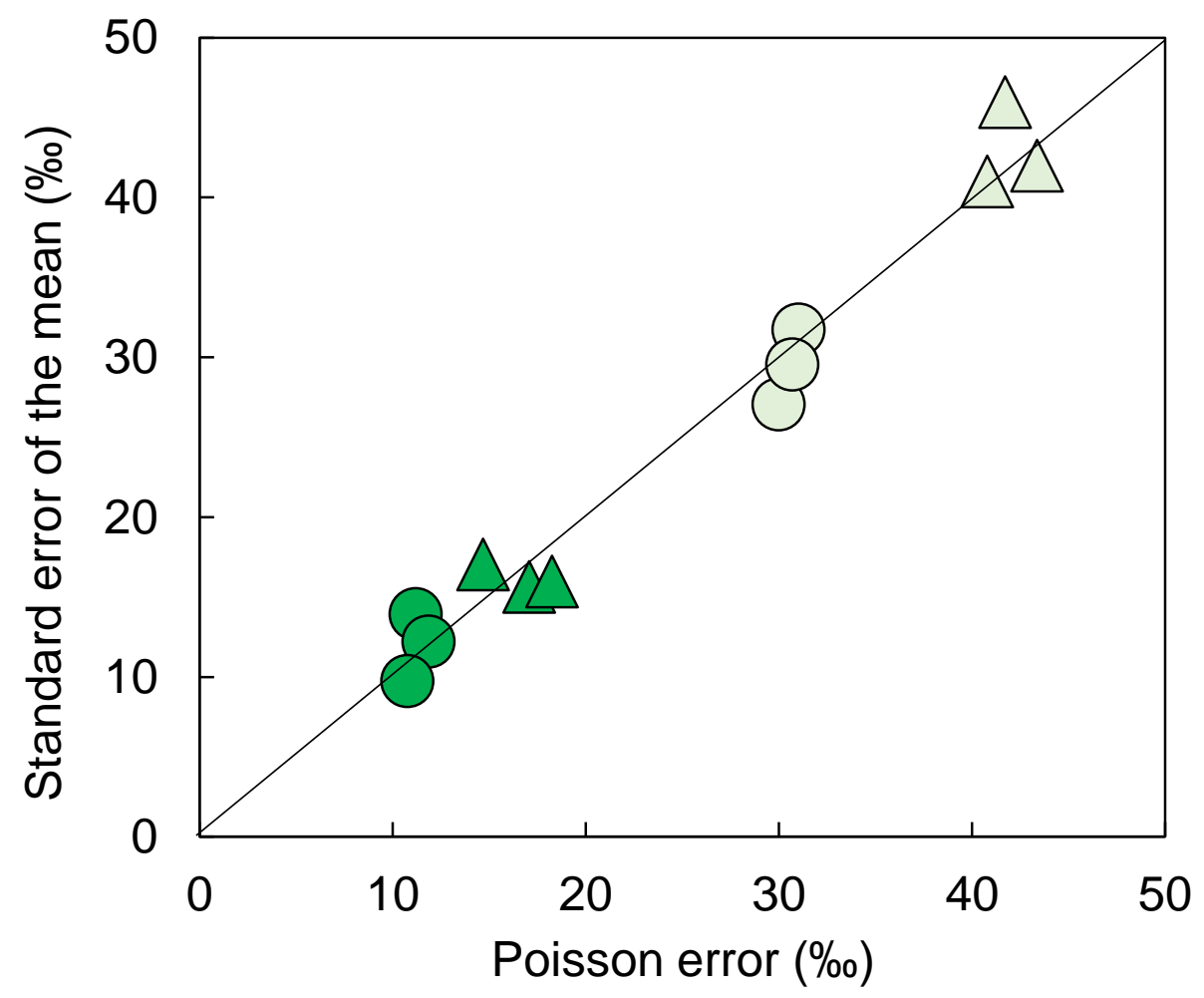

Figure S-8: Comparison of the average counting statistics of bulk FIB sections (deep green) and $1.6 \mu \mathrm{m}$ zones (light green) of FIB sections of Bamble (triangles) and Illimaussaq (circles) amphiboles calculated with Poisson statistics with the standard error of the mean between image planes for the same analyses. All points plot along the slope 1 meaning that using both calculations give approximately the same results. 


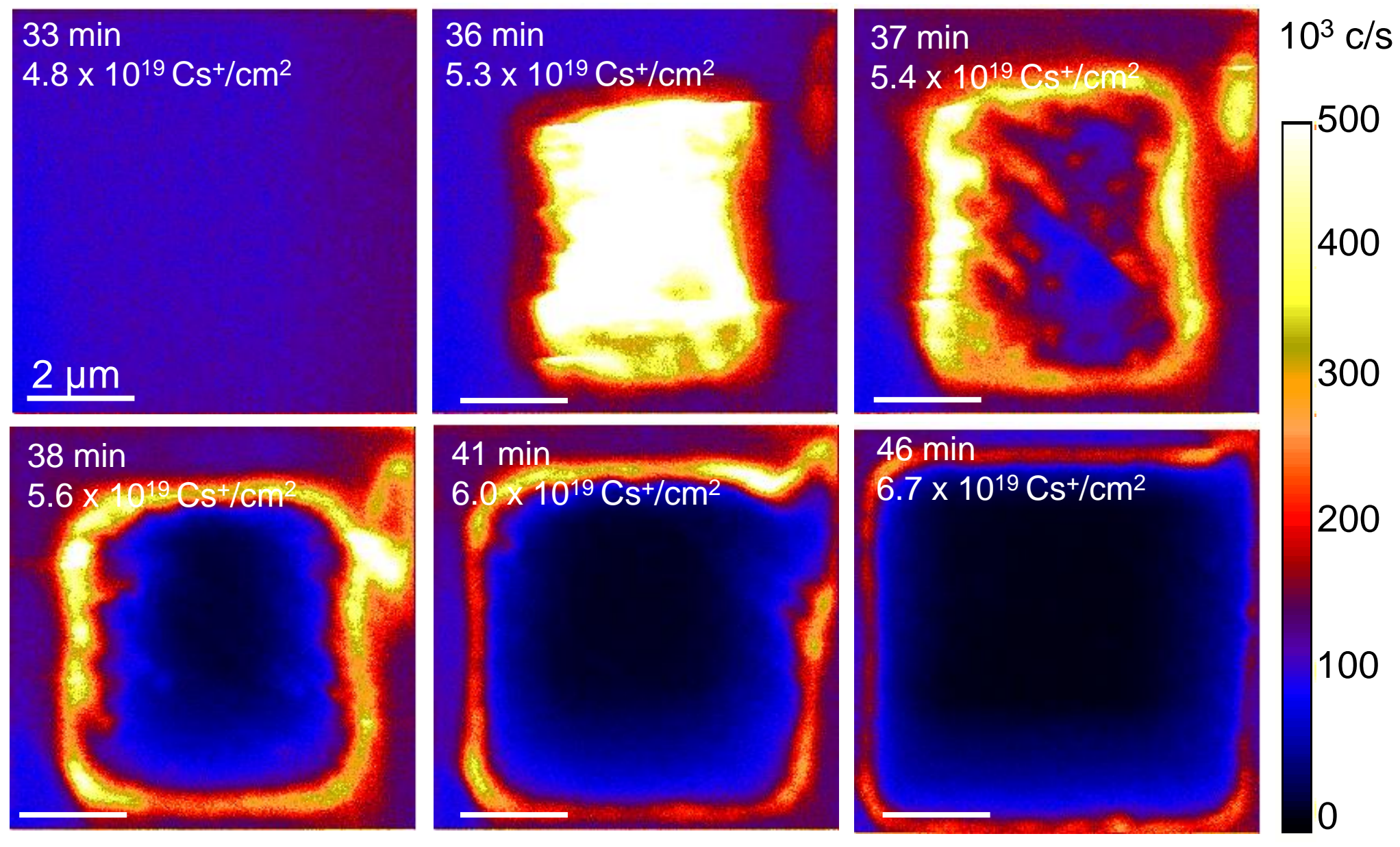

Figure S-9: Evolution of a $500 \mathrm{~nm}$ thick FIB section of Illimaussaq amphibole through time. After $36 \mathrm{~min}$, a high $\mathrm{H}^{-}$intensity is visible at the center of the ion image. It corresponds to the contamination at the surface of the $\mathrm{Al}$ mount that was protected from sputter cleaning during implantation by the FIB section and is revealed when the FIB section is gone. This contamination is removed in roughly $2 \mathrm{~min}$. The high $\mathrm{H}^{-}$intensity on the edge of the hole is attributed to topography enhancement of the the $\mathrm{H}^{-}$yield. Duration and $\mathrm{Cs}+$ dose $\left(\mathrm{ions} / \mathrm{cm}^{2}\right)$ are indicated. 


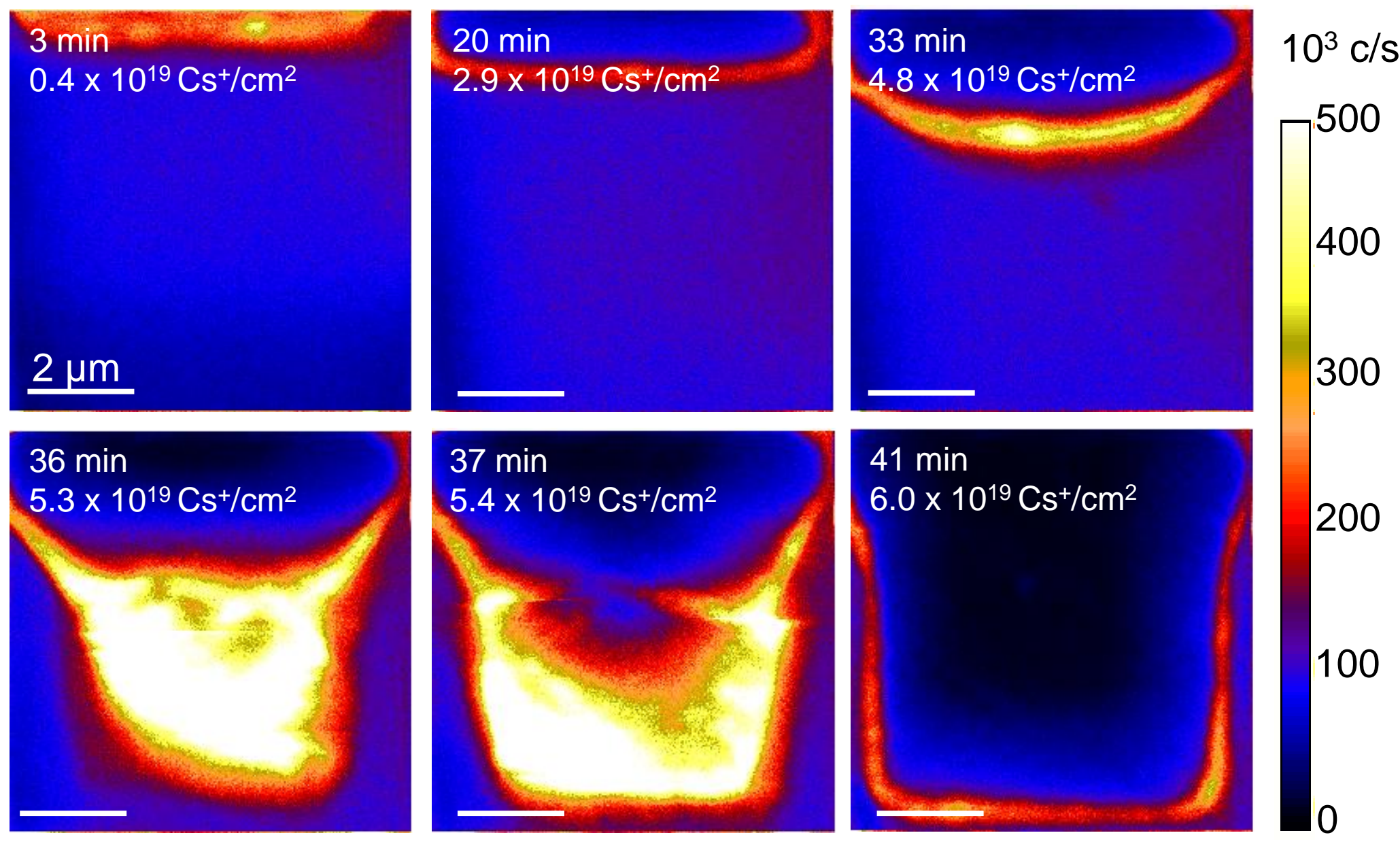

Figure S-10: Evolution of the $500 \mathrm{~nm}$ thick FIB section of Illimaussaq amphibole through time. Imaging was done next to the hole created during the sputtering experiment shown in Fig. S7. Between 0 and 33 min, the hole of the previous analysis expends by preferential erosion of the border (top of the image). At the $36^{\text {th }}$ minute a second hole forms in the center of FIB section as in Fig. S7. The high $\mathrm{H}^{-}$intensity can again be attributed to the contamination at the surface of the $\mathrm{Al}$ mount, removed in roughly $2 \mathrm{~min}$. Similarly the high $\mathrm{H}^{-}$intensity on the edge of the hole is due to topography. Duration and Cs+ dose $\left(\right.$ ions $\left./ \mathrm{cm}^{2}\right)$ are indicated. 


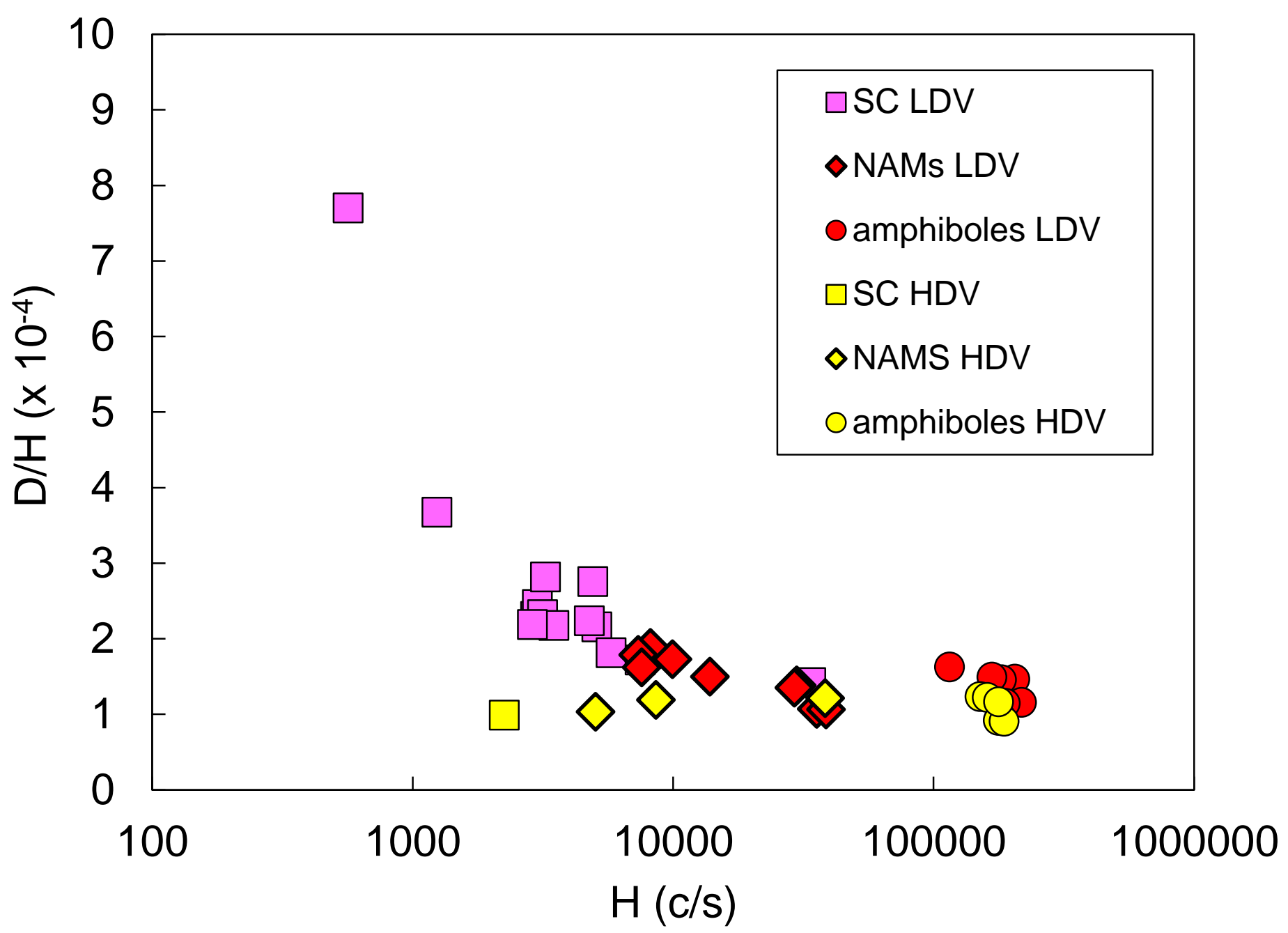

Figure S-11: D/H ratio plotted against hydrogen intensity. For a low EM2 deflector voltage (12 V, LDV), there is an increase in $\mathrm{D} / \mathrm{H}$ ratio when the hydrogen intensity of the samples decreases. For a high EM2 deflector voltage (111 V, HDV), the $\mathrm{D} / \mathrm{H}$ ratio is constant with hydrogen intensity and the Bamble and Illimaussaq amphiboles have the expected values (and difference relative to each other). 